\title{
LISTE DES ABRÉVIATIONS UTILISÉES DANS LES RÉFÉRENCES
}

AC............ Antiquité classique, Liège.

AE $\ldots \ldots \ldots \ldots$ Année épigraphique, Paris.

A.E.S.C. ....... Annales, Economie, Sociétés, Civilisations, Paris.

AJA...$\ldots \ldots \ldots$ American Journal of Archeology, Princeton.

AJPh ......... American Journal of Philology, Baltimore.

AS............. J. HARMAND, L'armée et le soldat à Rome de 107 à 50 av. notre ère.

$\mathrm{BCH} . \ldots \ldots \ldots \ldots$

CIL $\ldots \ldots \ldots \ldots$.

Bulletin de Correspondance Hellénique, Paris.

$\mathrm{CQ} \ldots \ldots \ldots \ldots \ldots$

CR.............

Corpus Inscriptionum latinarum.

CRAI .......... Comptes rendus de l'Académie des Inscriptions et Belles-Lettres,

HSCP $\ldots \ldots \ldots \ldots$ Harvard Studies in Classical Philology.

ILS $\ldots \ldots \ldots \ldots$ Inscriptiones latinae selectae.

JDAI ......... Jahrbuch des Deutschen Archäologischen Instituts, Berlin.

JHS .......... Journal of Hellenic Studies, London.

JRS . ........ Journal of Roman Studies, London.

MEFR .......... Mélanges d'Archéologie et d'Histoire de l'École française de Rome.

ORF $\ldots \ldots \ldots \ldots$ Oratorum Romanorum fragmenta.

RE .......... Paulys Real-Encyclopädie der klassischen Altertumwissenschaft.

REA ......... Revue des Etudes Anciennes, Bordeaux.

REG ......... Revue des Etudes Grecques, Paris.

REL ......... Revue des Etudes Latines, Paris.

RFIC ......... Rivista di Filologia e di Istruzione Classica, Torino.

RH $\ldots \ldots \ldots \ldots$ Revue historique, Paris.

RHD ......... Revue d'Histoire du Droit, Groningen.

RIA .......... Rivista dell'Istituto Nazionale di Archeologia e Storia dell'Arte, Roma.

RPh .......... Revue de Philoilogie, Paris.

RS $\ldots \ldots \ldots \ldots$ Römische Studien.

RSI............ Rivista storica italiana, Napoli.

SHA $\ldots \ldots \ldots \ldots$. Scriptores Historiae Augustee.

SVF .......... Stoïcorum veterum fragmenta.

TPAPha......... Transactions and Proceedings of the American Philological Association, Ithaca. 
